\title{
Evaluation of Selected Slaughterhouses and Parasites of Slaughtered Livestock in Cotabato Province, Mindanao, Philippines
}

\author{
C.M. Besana ${ }^{1,2^{*}}$ and V.G.V. Paller ${ }^{3}$
}

\begin{abstract}
${ }^{1}$ Department of Biological Sciences, College of Arts and Sciences, University of Southern Mindanao, Kabacan, Cotabato, ${ }^{2}$ Graduate School, University of the Los Baños, Laguna, Philippines ${ }^{3}$ Animal Biology Division, Institute of Biological Sciences, College of Arts and Sciences, University of the Los Baños, Laguna, Philippines

*corresponding author: cyrellembesana@gmail.com
\end{abstract}

Journal of Livestock Science (ISSN online 2277-6214) 11: 67-76

Received on 9/1/2020; Accepted on 11/3/2020

doi. 10.33259/JLivestSci.2020.67-76

\begin{abstract}
This study was carried out in four selected slaughterhouses with different facilities, processing operations, and management practices in Cotabato Province, Mindanao, Philippines. Facilities and equipment were evaluated in terms of presence and functionality. Slaughterhouse personnel were also interviewed to document each slaughterhouse's management practices. Blood, fecal, and organ samples were collected from 35 slaughtered swine and 15 slaughtered cattle. Furthermore, blood, fecal, and organ samples were processed and observed for the presence of different parasite stages. In swine, fecal examination showed an overall parasite prevalence of $60 \%$ in observed fecal samples. Parasites observed in fecal samples belong to subclass coccidia (42.86\%), Trichuris suis (8.57\%), hookworm/strongylid and Strongyloides sp. (5.7\%) and Ascaris suum (2.85\%). In cattle, fecalysis showed $53.3 \%$ prevalence for parasite eggs belonging to Fasciola sp. (33.3\%), amphistome and hookworm/strongylid (13.3\%), and Capillaria sp. (6.67\%). Adult parasites observed in slaughtered cattle were Fasciola sp. (33.3\%), amphistomes (26.67\%), and Setaria sp. $(6.7 \%)$. ELISA tests showed that all swine samples were seronegative for cysticercosis while $31.43 \%$ were seropositive for Toxoplasma. The present study also showed that most of the slaughterhouses observed have outdated facilities and equipment, as well as inadequate waste disposal systems. Inadequate budget allocation and funding remains to be the primary reasons hindering the upgrading of facilities, infrastructure, and equipment of the selected slaughterhouses. Furthermore, improper slaughterhouse waste disposal may contaminate the environment with infective forms of parasites and pathogens.
\end{abstract}

Keywords: Slaughterhouse facilities; operations; practices; Philippines 


\section{Introduction}

Slaughterhouses are considered as the primary establishments for preparation of animals for food consumption. In the Philippines, the accreditation of slaughterhouses and the implementation of guidelines and policies on proper management of meat and meat by-products are handled by the National Meat Inspection Services (NMIS) under the Department of Agriculture (Maranan et al., 2008). The provisions of the Code on Sanitation of the Philippines (P.D. 856) are among those adopted into the regular accreditation process of NMIS. The NMIS accredits three types of establishments: (a) slaughterhouses with proper facilities for export production (AAA), (b) establishments equipped to serve the domestic market (AA), and (c) those that can only distribute and trade their products within municipality or city (A).

The NMIS only accredited 13.2\% of the monitored slaughterhouses (NMIS Annual Report, 2014). Nineteen of which are "A" slaughterhouses. Furthermore, only six slaughterhouses can export meat or provide meat to "AAA" meat processing plants. Section 12 of the Meat Inspection of the Philippines states that the local government units shall endeavor to improve existing meat facilities to comply with the national standards; however, most slaughterhouses lack necessary funding for infrastructure development and equipment. Presumably, a large number of food animals slaughtered in the Philippines are processed in unregistered establishments where facilities are inadequate. In rural or local settings, slaughtering is often done either out in the open, under the trees, or in deteriorated and outdated slaughter units without any waste treatment facilities (Food and Agriculture Organization, 2014). Furthermore, animals with parasite infections may transmit zoonotic parasites to humans and contaminate the environment with eggs from their feces (McDaniel et al., 2014; Kumar et al., 2013; Murrel, 2013). These factors may contribute to unregulated butchering of livestock in unauthorized establishments increasing the exposure of meat, organs, and meat by- products to pathogens, which also increase the chance of contamination and spoilage of the meat products (Ninios et al., 2014). Furthermore, the presence of insect vectors such as flies and cockroaches may also increase the transmission of zoonotic diseases such as giardiasis, cryptosporidiosis, and taeniasis, from contaminated meat to humans and to other animals (Sarwar, 2015; Graczyk et al., 2005). Moreover, untreated slaughterhouse wastes also pose risks to the environment and public health since effluent from these facilities is highly polluted (Maranan et al., 2008). The effluent includes large amounts of solids, organic matter and nutrients, as well as pathogens and harmful bacteria.

This study aimed to evaluate the conditions, equipment, infrastructure and management practices in four slaughterhouse types and to identify parasites present in some livestock slaughtered in Cotabato Province, Philippines.

\section{Materials and Methods}

Ethical considerations

Before conducting the study, permission and approval was obtained from the heads and/or supervisors for each observed slaughterhouses. Furthermore, the observed slaughterhouses were assigned codes to maintain their privacy.

Study area

The study was conducted in four selected slaughterhouses with different management practices in Cotabato Province, Mindanao, Philippines (Figure 1). The study was conducted from May 2017 December 2017.

Four municipalities in Cotabato were randomly selected with each municipality having a representative slaughterhouses. The sampling sites were also selected based on the following criteria: (a) areas with previously reported occurrence of parasitic infections in cattle and swine, (b) areas with cattle and swine raisers, (c) peace-and-order situation, and (d) willingness of slaughterhouses to cooperate.

Survey

Pilot testing and validation of the questionnaires was done prior to the interview and survey. Informed consent was also sought from the key informants prior to interview. Key informants were interviewed using semi-structured questionnaires.

\section{Assessment of slaughterhouse equipment and practices}

Each selected slaughterhouse was visited during their slaughter operations, ranging from 8:00 PM - 5:00 AM. Slaughterhouse facilities and equipment were evaluated based on their presence and functionality. Conditions of infrastructure and slaughterhouse facilities were also noted.

\section{Research design}

This study utilized random sampling whereby 35 slaughtered swine were selected to detect $60 \%$ parasite prevalence at $80 \%$ statistical power and 5\% level of significance, assuming $80 \%$ parasite prevalence in the population. On the other hand, 15 slaughtered cattle were selected to detect $15 \%$ parasite prevalence at $80 \%$ power and $5 \%$ level of significance assuming $52 \%$ parasite prevalence in the population (Stata ver. 13.1, College Station, Texas, 77845, USA). 


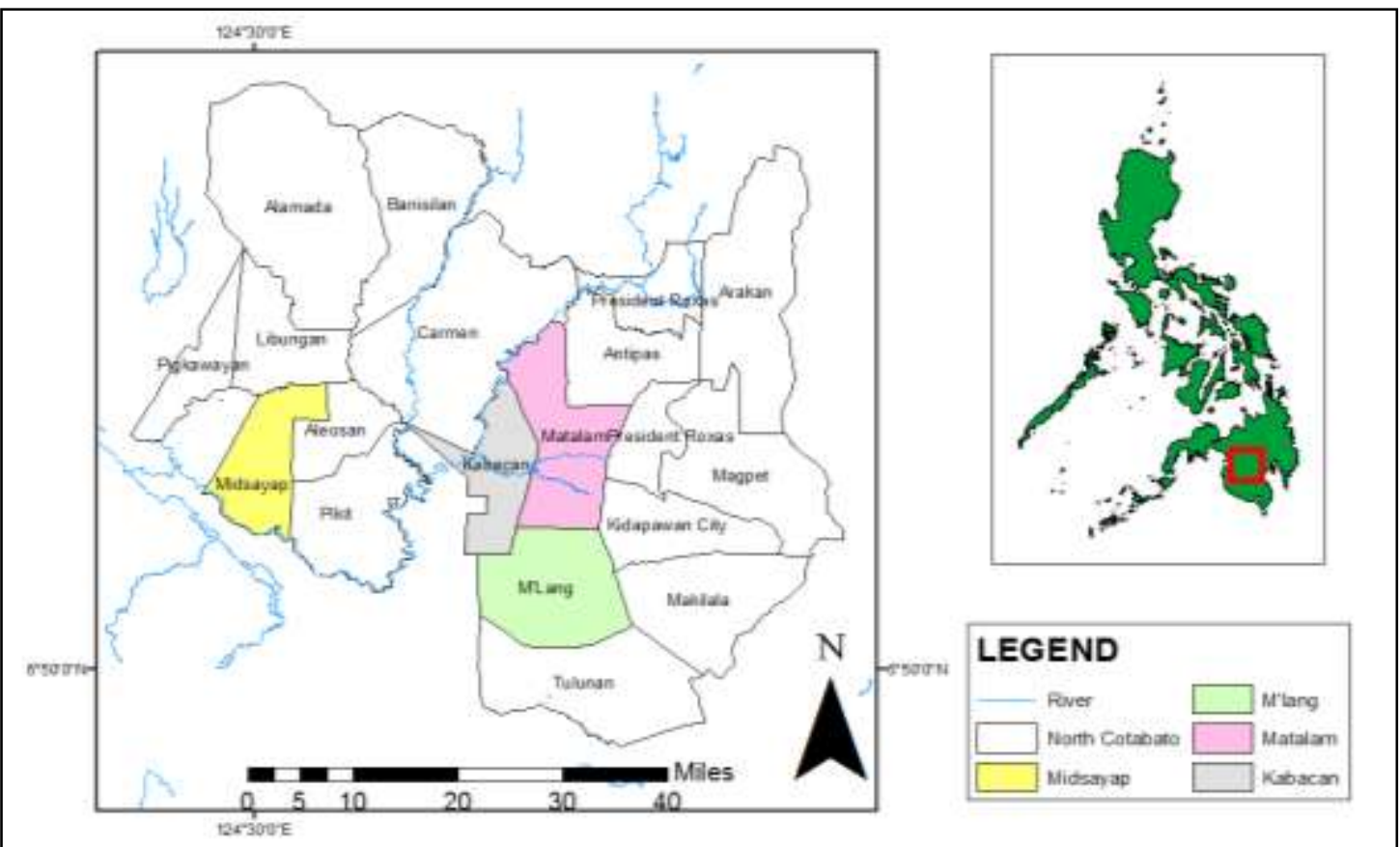

Fig 1. Map of Cotabato Province, Mindanao, Philippines

\section{Examination of samples}

Visual inspection was done in slaughtered animals during regular slaughtering processes in each slaughterhouse with the help of a veterinarian. Furthermore, fecal and organ samples (liver, small intestine, lungs, large intestine) from slaughtered pig $(n=35)$ and cattle $(n=15)$ were also collected from the observed slaughterhouses. The sex and source of the animals were also recorded. The samples were packed in iced containers and taken to the laboratory for examination. Samples that were not examined on the same day as the collection were stored at $-20^{\circ} \mathrm{C}$ until further observation.

Approximately $3.5 \mu \mathrm{l}$ of blood samples were collected during the bleeding of slaughtered animals. Samples for serological examination were placed in serum separating tubes and placed in an iced container for transport to the laboratory for processing (Kalai et al., 2011). The sera were separated through centrifugation of the tubes at $1500 \mathrm{rpm}$ for 10 minutes. Collected sera were transferred to properly labelled sterile microcentrifuge tubes aliquots and then stored at $-20^{\circ} \mathrm{C}$. Blood samples were also collected from slaughtered pigs for enzyme linked immunosorbent assay (ELISA) to detect cysticercus and Toxoplasma antibodies in slaughtered swine samples.

The organs of slaughtered livestock were also observed for pathologic lesions and other abnormalities post-mortem with the help of a veterinarian and deputized meat inspectors. Sections of the small and large intestines, lungs, and liver were randomly collected from slaughtered animals. Organ samples were then dissected and observed for the presence of adult and larval stages of helminth parasites while rectal contents were collected for fecal examination using formalin ethyl acetate concentration technique (FEACT).

\section{Data Analysis}

Qualitative data that were obtained from key informant interview discussions were transcribed and analyzed using coding and thematic analysis. Descriptive statistics were used to summarize the results of KI interviews.

Prevalence of parasites in swine and cattle from the selected slaughterhouses was calculated using the following formula:

$$
\text { Prevalence }=\frac{\text { total number of infected animals }}{\text { total number of animals }} \times 100
$$

\section{Results}

All of the observed slaughterhouses are registered locally and are owned by their respective municipalities. Out of these, only one was registered and accredited by the National Meat Inspection Service. Furthermore, the four slaughterhouses vary from each other in terms of equipment, facilities, and operations. 


\section{Slaughterhouse facilities and operations}

The number of livestock slaughtered in the observed slaughterhouses varies. According to the interviewed personnel, there are months where there is an increase in the number of slaughtered livestock, usually during major holidays, and there are also lean months where the number of slaughtered livestock was low. At the time of the interview, Slaughterhouse C001 was experiencing lean months. The average numbers of slaughtered animals were the following: cattle ( 2 heads/day), pigs ( 22 heads/day), goat ( 2 heads/day). Slaughterhouse C002 has a daily average of: cattle (8 to 9 heads/day), pigs (15 heads/ day); Slaughterhouse C003 has a daily average of approximately: cattle ( 1 to 2 heads/ day), pigs ( 9 heads/ day). For Slaughterhouse C004, the daily slaughter average of: cattle (10 heads/day), pigs (30 heads/ day). Aside from Slaughterhouse C001 goats were also slaughtered in other observed slaughterhouses but only occasionally, usually for personal consumption.

Slaughterhouse C001 is located about $200 \mathrm{~m}$ from residential areas. It follows a standard design mandated by the NMIS which includes an enclosed building with concrete floors and walls, as well as clearly demarcated areas for the different steps involved in slaughtering (Table 1). Hand dips and tool dips, hand-washing facilities, footbaths with disinfectant, and water outlets were also placed strategically around the slaughter area. Slaughterhouse C004 is also made of enclosed concrete walls and floors with designated areas for bleeding, scalding, dehairing, evisceration, splitting, and processing of carcass. There is also a separate room for cleaning, inspecting, and processing offal. On the other hand, Slaughterhouse C002 and Slaughterhouse $\mathrm{C} 003$ are made up of concrete with partially enclosed slaughter areas. They also have poorly demarcated areas for processing the slaughtered animals. Furthermore, unlike the other slaughterhouses observed, Slaughterhouse C003 does not have separate areas for slaughtering cattle and pigs. All of the slaughterhouses have gates enclosing its perimeter. However, during observation, dogs were seen roaming in Slaughterhouse C001, C003, and C004 as the gates were opened during operations to allow the movement of vehicles transporting animals and dressed meat. Cockroaches were also observed around the swine slaughter area in Slaughterhouse C002.

All of the observed slaughterhouses schedule their operations between 8:00 PM and end at 5:00 AM onwards or until all animals are processed and sent out. Out of the slaughterhouses observed, only Slaughterhouse $\mathrm{C} 001$ has semi-automated operations, while the others have manual operations. Furthermore, only Slaughterhouse C001 had a semi-automated hot water system with hoists and rails while the other slaughterhouses utilized manual scalding of carcasses by dipping them in large iron pans or vats where water is heated using wood-fired stoves. All slaughterhouses, except Slaughterhouse C001 and the swine slaughtering area in Slaughterhouse C004, practice floor slaughtering where processing activities ranging from stunning to dressing meat for market transport are done on bare cement floors. Only Slaughterhouse $\mathrm{C} 001$ had a dedicated meat van for transporting dressed meat from the Slaughterhouse to the market. In other Slaughterhouses, dressed meat is transported using a motorcycle with attached semiopen sidecars. The transport of meat is usually done by the butcher and workers employed by individual livestock owners or meat vendors.

\section{Water sources}

All observed slaughterhouses have their own water sources, mostly in the form of deep wells. A continuous water supply is essential for slaughterhouses as water is needed in every stage of slaughter operations, especially for scalding and dehairing of animals. It is also important for cleaning the floors of the slaughter area before and after slaughtering. Three out of the four observed Slaughterhouses use water, soap, and disinfectant for cleaning while the remaining only used pressurized water.

\section{Waste disposal}

Disposal of wastes, fecal material, and other by-products during and after slaughter also varies. In Slaughterhouse C001, wastewater, damaged offal, parasites, feces, and other gastrointestinal contents go straight from the offal cleaning area canal into a lagoon located at the back of the Slaughterhouse. Similarly, wastewater and other by-products are also disposed in a lagoon in Slaughterhouse C004. However, according to the butchers interviewed, the condemned or damaged meat and organs are buried at the back of the slaughterhouse, while damaged livers are usually burned within the slaughterhouse premises to prevent stray dogs from eating them. Slaughterhouses C002 and C003 both dispose wastewater, blood, and gastrointestinal contents through canals which drain to an irrigation canal and a creek, respectively.

\section{Slaughterhouse personnel}

Slaughterhouse personnel equipment with focus on personal protective equipment (PPE), operations, and processes were also observed during slaughter operations (Table 2). Two (C001 and C004) out of the observed slaughterhouses have butchers wearing complete protective gear composed of aprons, boots, gloves, masks, and hairnets. These slaughterhouses were the NMIS accredited and previously accredited slaughterhouses. On the other hand, one slaughterhouse requires all butchers to wear at least a pair of boots during slaughter processes, while the remaining does not require any protective gear at all. In some cases, butchers were observed processing animal carcasses without clothes or footwear. Butchers were also seen 
smoking within the slaughter floor during slaughter operations. Furthermore, there are several instances where butchers were observed spitting on slaughter floors during slaughter operations. Butchers from three out of the four slaughterhouses were required to have annual check-ups and health certificates while one out of the four slaughterhouses have butchers with expired health certificates.

Table 1. Equipment and facilities of selected slaughterhouses in Cotabato Province, Mindanao, Philippines

\begin{tabular}{|c|c|c|c|c|}
\hline \multirow[t]{2}{*}{ Equipment, facilities, and structures } & \multicolumn{4}{|c|}{ Slaughterhouse } \\
\hline & $\mathrm{C} 001$ & $\mathrm{C} 002$ & $\mathrm{C} 003$ & $\mathrm{C} 004$ \\
\hline Gates & + & + & + & + \\
\hline \multicolumn{5}{|l|}{ Slaughter area } \\
\hline Enclosed & + & - & - & - \\
\hline Partially enclosed & & + & + & + \\
\hline \multicolumn{5}{|l|}{ Demarcated areas for different slaughter processes } \\
\hline Bleeding area & + & - & - & - \\
\hline Evisceration area & + & - & - & - \\
\hline Scalding area & + & - & - & - \\
\hline Dehairing area & + & - & - & - \\
\hline Splitting area & + & - & - & - \\
\hline Separated Slaughter Areas for Cattle and Swine & + & + & - & + \\
\hline \multicolumn{5}{|l|}{ Operations } \\
\hline Semi-automated & + & - & - & - \\
\hline Manual & - & + & + & + \\
\hline Overhead rail system & $+^{* \mathrm{c}}$ & - & - & $+^{\mathrm{c}}$ \\
\hline Slaughter tables & $++^{* \mathrm{c}}$ & - & - & $+^{*}$ \\
\hline Holding pens & $+* \mathrm{c}$ & $+*$ & $+*$ & $+^{* c}$ \\
\hline Hot water system & $+^{* \mathrm{c}}$ & - & - & - \\
\hline Offal cleaning area/ room & + & - & - & + \\
\hline \multicolumn{5}{|l|}{ Wastewater Disposal } \\
\hline $\begin{array}{l}\text { Lagoons } \\
\text { Creek/waterways }\end{array}$ & + & - & $\bar{z}^{+}$ & + \\
\hline Water Source & + & + & + & + \\
\hline \multicolumn{5}{|l|}{ Transportation of meat and meat by-products } \\
\hline Meat van & + & - & - & - \\
\hline Motorcycles with attached sidecars & + & + & + & + \\
\hline \multicolumn{5}{|l|}{ Animals Observed } \\
\hline Cockroaches & - & $+*$ & - & - \\
\hline Dogs & + & - & + & + \\
\hline Rats & - & - & - & - \\
\hline
\end{tabular}

$(*)$ swine only $\left({ }^{c}\right)$ cattle only $\left(*^{c}\right)$ cattle and swine $(+)$ present $(-)$ absent

Table 2. Personnel equipment, operations, and processes in selected slaughterhouses in Cotabato, Province, Mindanao, Philippines

\begin{tabular}{|l|l|l|l|l|}
\hline $\begin{array}{l}\text { Personnel equipment, } \\
\text { operations and processes }\end{array}$ & \multicolumn{5}{c|}{ Slaughterhouse } \\
\hline & C001 & C002 & C003 & C004 \\
\hline Uniforms & + & - & - & + \\
\hline Protective gear & & & & \\
\hline Aprons & + & - & - & + \\
\hline Boots & + & - & + & + \\
\hline Gloves & + & - & - & - \\
\hline Masks & + & - & - & - \\
\hline Hairnets & + & - & - & - \\
\hline Health certificates & + & - & + & + \\
\hline Annual check-ups & + & - & - & + \\
\hline Formal training in butchery/ slaughterin & + & - & + & - \\
\hline Nature of employment of butchers & & & & \\
\hline Permanent & - & - & - & - \\
\hline “Pakyaw” or per head basis & + & + & + & + \\
\hline Employer & & & & \\
\hline Slaughterhouse (i.e. job order personn & + & - & - & + \\
\hline Privately employed & - & + & + & - \\
\hline Trainings (e.g. GMP) & + & - & - & + \\
\hline
\end{tabular}

In terms of formal training in butchery and slaughter processes, only one of the slaughterhouses observed have trained personnel while the other observed slaughterhouses have not received formal trainings. Some of the interviewed butchers stated that their knowledge in slaughtering animals have been 
acquired through years of experience and by observing other experienced butchers. The butchers' nature of employment was based on per head or "pakyaw" basis. None were permanently employed by each respective slaughterhouse. Furthermore, most meat vendors employ their own butchers who are in charge with processing and transporting slaughtered swine from the slaughterhouse to the market stalls. Furthermore, only two of the observed slaughterhouses have butchers with trainings on animal welfare, Hazard Analysis and Critical Control Points (HACCP), Good Manufacturing Practices (GMP) and Sanitation Standard Operating Procedures (SSOP).

\section{Parasites observed in selected slaughtered animals from the observed slaughterhouses}

Blood, fecal, and organ samples were collected from 35 slaughtered swine and 15 slaughtered cattle. These samples were processed and observed for the presence of different parasite stages.

\section{Parasites in swine}

In swine, fecal examination showed an overall parasite prevalence of $60 \%$ in observed fecal samples. Parasites observed in fecal samples belong to subclass coccidia (42.86\%), Trichuris suis $(8.57 \%)$, hookworm/strongylid and Strongyloides sp. (5.7\%) and Ascaris suum (2.85\%) (Figure 2).

Although some fecal samples from the same animals have been found to be positive for the presence of helminth eggs, adult helminths which were large enough to be seen by the naked eye such as A. suum, Metastrongylus sp. and Trichuris suis were not observed from both the dissected samples and from the observations made during the viscera cleaning process from the slaughterhouses. This may be due to some practices of swine raisers where they deworm their animals before marketing, or before sending animals for slaughter. Furthermore, the observed eggs may be residual eggs of adult helminths that had been already expelled after deworming. However, the results may also be attributed to the extent of observation of the organs. Moreover, the presence of the adult stages of Strongyloides sp. may have been overlooked because of their very small size. On the other hand, a total of 35 blood samples from slaughtered pigs were collected from the four observed slaughterhouses and subjected to enzyme linked immunosorbent assay (ELISA) using commercial kits for detection of cysticercosis and toxoplasmosis. Out of these, none were positive for cysticercosis antibodies while eleven out of these samples $(31.43 \%)$ were positive for Toxoplasma antibodies.

\section{Parasites in cattle}

In cattle, fecal analysis showed $53.3 \%$ prevalence for parasite eggs belonging to Fasciola sp. (33.3\%), amphistome and hookworm/strongylid (13.3\%), and Capillaria sp. (6.67\%) (Fig 3). Adult parasites observed in slaughtered cattle were Fasciola sp. (33.3\%), amphistomes (26.67\%) (Fig 4), and Setaria sp. $(6.7 \%)$.

\section{Discussion}

According to the section 12 of the National Meat Inspection Code of the Philippines (R.A. 9296) (2005), the local government units should endeavor to improve meat facilities in order to comply with the national standards. In the study, only one out of the four observed slaughterhouses was accredited by the NMIS, while the others are only locally registered. This may be due to the fact that the other slaughterhouses have not met the national standards for slaughterhouses. Furthermore, these unaccredited slaughterhouses may increase the consumers' exposure to pathogens due to non-compliance to the meat hygiene program (Maranan et al., 2008). Slaughterhouse C001 was the only NMIS accredited slaughterhouse and is located approximately $200 \mathrm{~m}$ from residential areas. Slaughterhouse C004 was also previously accredited by the NMIS as an "AA" slaughterhouse. However, it has not maintained its accreditation because it is located in a residential area. Similarly, Slaughterhouse C002 was also located in a residential area, while Slaughterhouse C003 was located near the public market. The NMIS suggests that slaughterhouses should be located far from any building used for human habitation, and from any factory, public place, and should be free from dust, odor, smoke, and other contaminants (NMIS Guidebook for Design and Construction of Slaughterhouse). In terms of slaughterhouse equipment and facilities, only one had a complete overhead rail system with hoists, hooks and gambrels, slaughter tables, and hot water system.

Contamination may occur during processing of carcasses. The sources of contamination may include the slaughter facilities equipment, workers, and environment (Jay, 1992). The use of overhead rail systems during slaughter operations eliminates the contact of meat with the floor where there is a risk of meat exposure to dirt and pathogens (Mummed and Webb, 2015). Furthermore, a continuous supply of hot water is important during scalding and dehairing of slaughtered animals, especially swine. A semi-automated system comprised of boilers and hoists allows efficient processing of swine carcass. The absence of these equipment in the unaccredited, locally registered slaughter facilities indicate floor slaughtering, which do not require these tools (Maranan et al., 2008). Floor slaughtering may lead to an increased microbial load of meat and meat products (Kumar et al., 2014). It also exposes the carcasses to the bacterial, viral, 
chemical, and other contaminants that might be present on the floors (Maranan et al., 2008). Microbial contamination of carcasses mainly occur during skinning, evisceration, processing, storage, transportation and distribution in slaughterhouses and retail establishments (Gill , 1998). Furthermore, a study by Barros et al. (2007) found that the main bacterial contamination points in slaughterhouses are the platforms, floors, and drains. Moreover, the presence of cockroaches and dogs in the premises of the slaughterhouses increase the risks of contamination of the slaughterhouse environment. Cockroaches may contaminate the environment, as well as meat and meat by-products in the slaughterhouses because they serve as passive carriers of different microorganisms and helminths (Ninios et al., 2014).

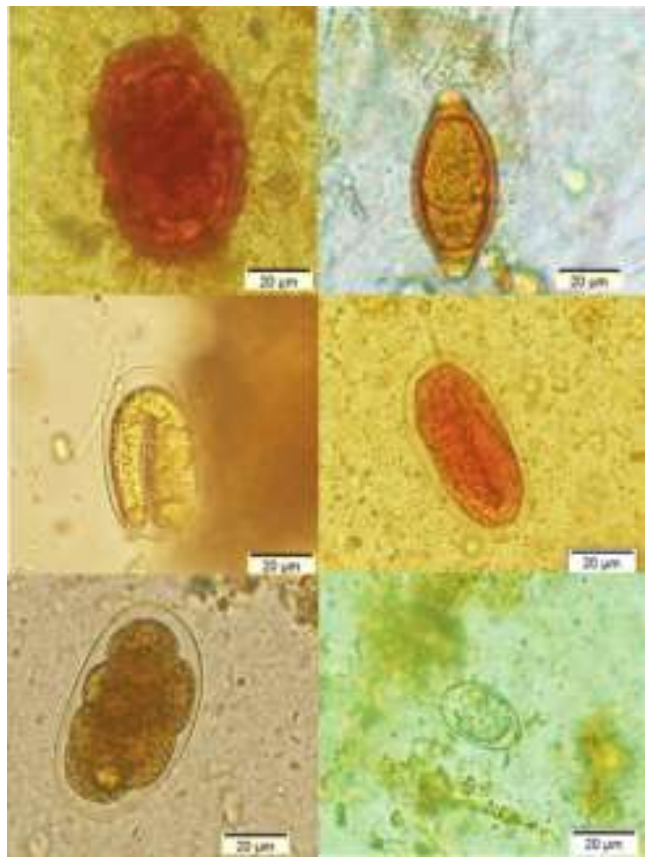

Fig 2. Parasites recovered from fecal samples of slaughtered swine from selected slaughterhouses in the Province of Cotabato: (a) Trichuris suis, embryonated egg, (b,c,d) Hookworm/ strongylid eggs, embryonated, (e) Ascaris suum, fertilized egg, (f) Isospora spp., unsporulated oocyst.

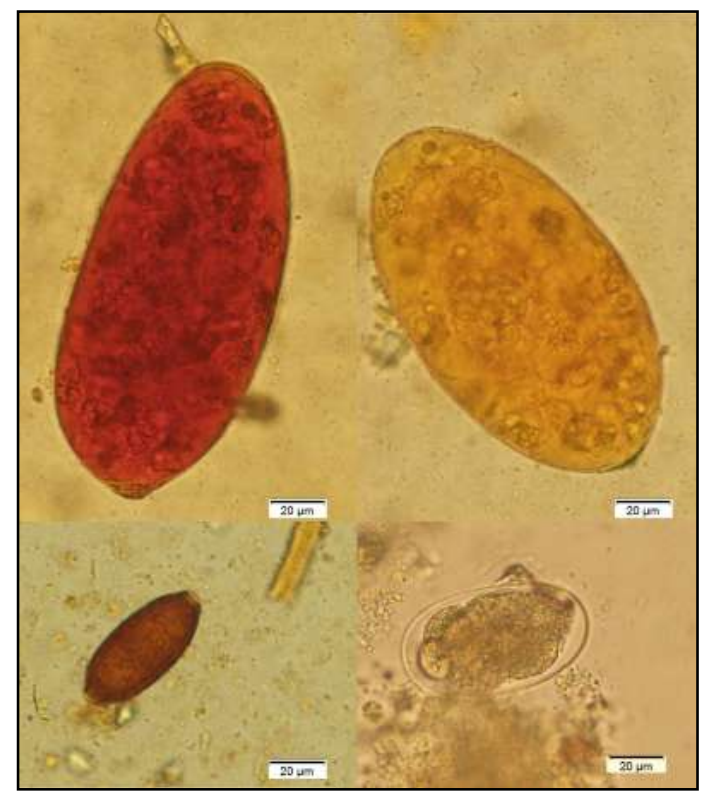

Fig 3. Parasites recovered from fecal samples of slaughtered cattle from selected slaughterhouses in the Province of Cotabato, (a) Fasciola spp.; (b) Paramphistomum sp.; (c) Capillaria spp.; (d) Hookworm/strongylid 


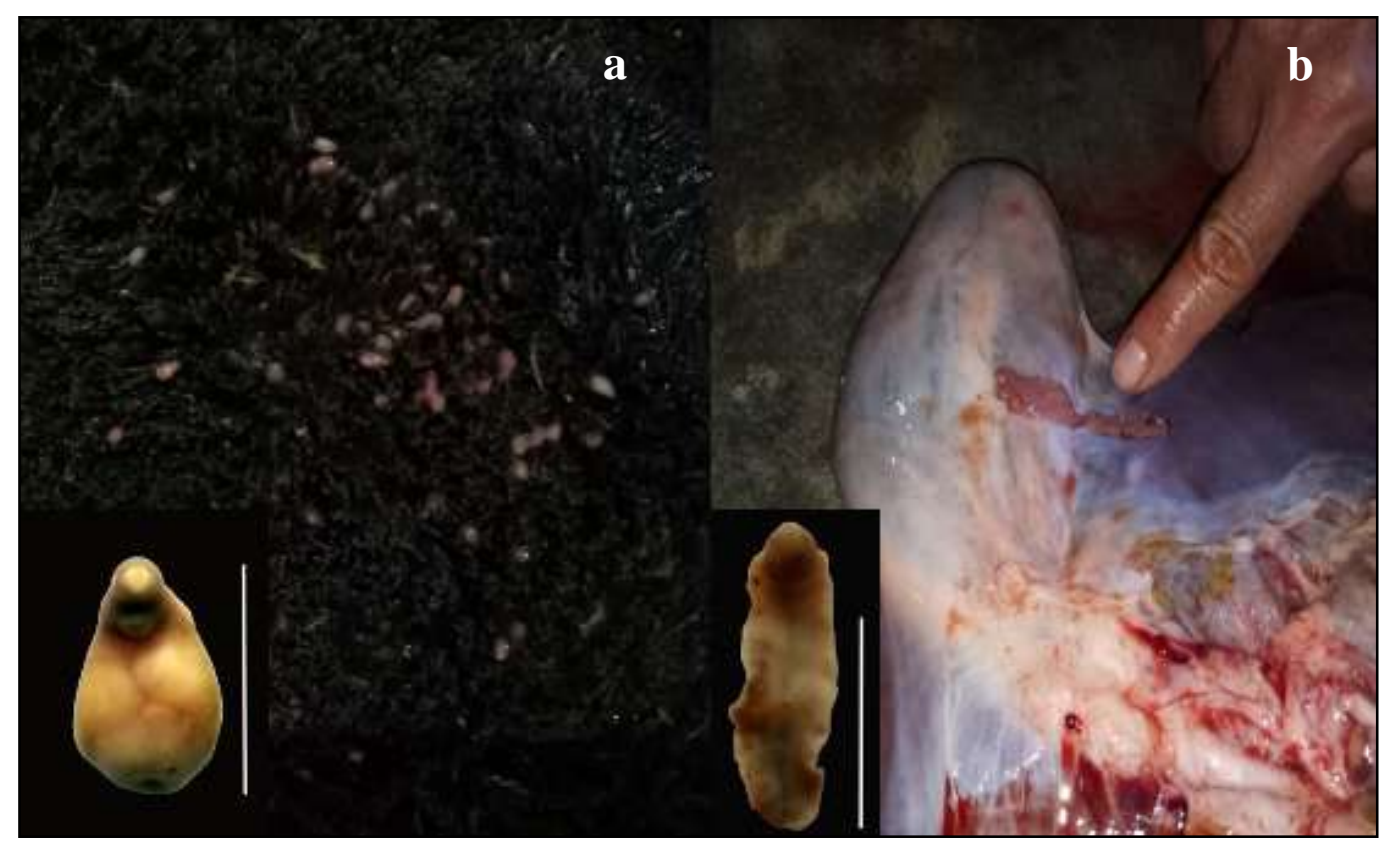

Fig 4. Adult flukes observed during post-mortem examination of slaughtered cattle from selected slaughterhouses in the Province of Cotabato, (a) Paramphistomum cervi in rumen; (b) Fasciola spp. from the liver. (scale bar $=10 \mathrm{~mm}$ )

In terms of waste disposal, the evaluated slaughterhouses also varied. Out of the four slaughterhouses, two dispose wastewater, blood, and gastrointestinal contents into lagoons at the back of the slaughterhouses. The other two dispose wastes into a small canal that is connected to an irrigation canal and a creek, respectively. Disposal of damaged organs in slaughterhouses also varies. In the absence of proper storage areas for damaged organs, some of the observed slaughterhouses burned and buried the organs around the premises of the slaughterhouse to prevent animals from eating them. Slaughterhouse wastes are considered as more complex than farm-generated wastes due to the wide range of substances and pathogens that they contain, as well as their understated effects to the environment (Rosengren et al., 2010;Sarairah and Jamrah, 2008). Poor management of slaughterhouses and their wastes may result in air and water pollution (Abdullahi et al., 2015).The amount of wastes and microbial organisms obtained during slaughterhouse operations may pose many challenges, not only to environmental health, but also to human populations residing in close proximity to the slaughterhouses (Adeyemo, 2002). Aside from manure, urine, and condemned animals, slaughterhouse wastes also include high concentrations of blood and suspended solids such as fat, grease, hair, flesh, proteins, fibers and undigested food (Mulu et al., 2013; Sarairah and Jamrah, 2008). The continuous discharge of slaughterhouse wastewater effluents to different bodies of water may result to the increase of organic matter, nitrogen, phosphorus, and solids, potentially resulting to eutrophication thereby decreasing the dissolved oxygen (DO), and increasing the biological oxygen demand (BOD). Aside from organic wastes and by- products which may cause eutrophication when released in bodies of water, slaughterhouse wastewater may also harbor pathogens which may cause disease in animals and humans. These pathogens include bacteria such as Campylobacter, Escherichia coli 0157:H7, Salmonella, and Yersinia, and parasites such as Balantidium coli, Cryptosporidium sp., Giardia lamblia, Entamoeba spp., Ascaris suum, Dicrocoelium sp., Fasciola spp., Moniezia sp., Trichostrongylus sp., and Trichuris spp. (Hatam-Nahavandi et al., 2015).

Furthermore, parasitic particles including helminth ova and protozoan (oo) cysts are more frequently detected in wastewater and are resistant to chlorination (Levine and Asano, 2004). Moreover, one of the major causes of gastroenteritis transmitted worldwide are pathogenic protozoa (Huang and White, 2006). Several waterborne amoebiasis, balantidiasis, cryptosporidiosis, cyclosporiasis and microsporidiasis outbreaks have been reported worldwide (Karanis et al., 2007).

Hygiene practices play an important role in reducing the spreading of spoilage and pathogenic bacteria during slaughter operations. These practices ensure that the product, meat specifically, is fit for human consumption (Ninios et al., 2014). Slaughterhouse personnel have key roles in preventing contamination 
during slaughter operations. This is because the common route of cross-contamination is through the hands and tools of butchers which are in contact with the hide and intestines of slaughtered animals. Furthermore, slaughter personnel can also be direct sources of bacteria and viruses (Ninios et al., 2014). Only half of the observed slaughterhouses require personnel to wear protective clothing. In slaughterhouses, the main purpose of wearing protective clothing is to protect the meat product from contamination. It also provides the butchers protection against zoonotic pathogens including leptospirosis and brucellosis (Palmer et al., 2011). Therefore, slaughterhouse workers who work with bare feet have an increased risk of harboring these diseases. According to Cook et al. (2017), the cost of protective clothing such as aprons and boots are the limiting factor because a majority of slaughterhouse workers must provide their own protective clothing.

Smoking was also observed during slaughter operations in some of the observed slaughterhouses. Smoking has been associated with an increased risk of zoonotic diseases (Campagnolo et al., 1998). On the other hand, spitting on the slaughter floors may cause not only the contamination of meat products, but also increases the risks of transmitting communicable diseases from one person to another. This is particularly important in slaughterhouses where personnel have not undergone annual check-ups. This is because an asymptomatic person with a communicable disease may transmit the disease unknowingly through spitting or through contaminated materials such as knives. Thus, it is important to train personnel in meat hygiene on order to improve conditions in slaughterhouses and to reduce bacterial contamination of meat and disease exposure in workers.

\section{Conclusion}

Based on the observations, most of the slaughterhouses observed have old and damaged structures and outdated equipment which were not compliant with the NMIS standards. This may hamper the slaughterhouses' efficiency and may also pose risks to public health. Problems in budget allocation and funding remains to be the primary reasons hindering the upgrading of facilities, infrastructure, and equipment of the selected slaughterhouses. Therefore, there is a need for the government, as well as important stakeholders, to provide personnel training in best practices, Hazard Analysis and Critical Control Points (HACCP), and other related trainings. Furthermore, as most slaughterhouses in municipalities are self-sufficient, provision of budget for improvement of facilities should be done in order to increase their efficiency and to ensure the provision of clean and healthy meats for its consumers. Moreover, sanitation and waste management should also be improved to prevent transmission of pathogens which may be present in by-products and waste of slaughtered animals, as well as enrichment and pollution of waterways and bodies of water.

\section{Acknowledgements}

The author/s would like to acknowledge the following: the respondents, for participating in this study and the Department of Science and Technology - Accelerated Science and Technology Human Resource Development Program (DOST-ASTHRDP) for supporting this research.

\section{Conflict of interest}

There is no conflict of interest in this study.

\section{References}

1) Abdullahi A, Kadarman N, Hassan A, Madobi IS,2015. Negative impact of slaughterhouse activities and management in residential neighbourhoods in Kuala Terengganu, Malaysia. International Journal of Medical Science and Public Health 4(3):124-130.

2) Adeyemo OK, 2002. Unhygienic operation of a city slaughterhouse in South-western Nigeria: environmental implication. African Journal of Environmental Science and Technology 4(1):23-28.

3) Barros MDF, Nero LA, Monteiro AA, Beloti V, 2007. Identification of main contamination points by hygiene indicator microorganisms in beef processing plants. Food Science and Technology 27(4):856-862.

4) Campagnolo ER, Warwick MC, Marx HL Jr, Cowart RP, Donnell HD Jr, Bajani MD, Bragg SL, Esteban JE, Alt DP, Tappero JW, Bolin CA , Ashford DA, 2000. Analysis of the 1998 outbreak of leptospirosis in Missouri in humans exposed to infected swine. Journal of the American Veterinary Medical Association 216(5):676-682.

5) Cook EA, De Glanville WA, Thomas LF, Kariuki S, Bronsvoort BMD, Fevre EM, 2017. Working conditions and public health risks in slaughterhouses in western Kenya. BMC Public Health 14: 112. DOI: $10.1186 / \mathrm{s} 12889-016-3923-y$

6) Food and Agriculture Organization of the United Nations (2014, November 25). Slaughtering Facilities. Retrieved from http://www.fao.org/ag/againfo/themes/en/meat/slaughtering.html 
7) Gill CO, 1998. Microbiological contamination of meat during slaughter and butchering of cattle, sheep and pigs. In: DAVIES, A.; BOARD, R. (Eds.). The Microbiology of Meat and Poultry. London: Blackie Academic and Professional, pp. 118-157.

8) Graczyk TK, Knight R, Tamang L. 2005. Mechanical transmission of human protozoan parasites by insects. Clinical Microbiology Reviews 18(1):128- 132.

9) Hatam-Nahavandi K, Mahvi AH, Mohebali MM, Keshavarz H, Mobedi I, Rezaeian M. 2015. Detection of parasitic particles in domestic and urban wastewaters and assessment of removal efficiency of treatment plants in Tehran, Iran. Iranian Journal of Environmental Health Science and Engineering 13(4):1-13. DOI: 10.1186/s40201-015-0155-5

10) Huang DB, White AC, 2006. An updated review on Cryptosporidium and Giardia. Gastroentorology Clinics of North America 35(2): 291-314.

11) Jay JM. 1992. Modern food microbiology. New York, NY: Van Nostrand Reinhold.

12) Kalai K, Nehete RS, Ganguly S, Ganguli M, Dhanaklakshmi S, Mukhopadhayay SK. 2012. Investigation of parasitic and bacterial diseases in pigs with analysis of haematological and serum biochemical profile. Journal of Parasitic Diseases 36(1):129-134. DOI: 10.1007/s12639-011-0068-x

13) Kumar P, Rao J, Manjunath Y. 2014. Microbiological quality of meat collected from municipal slaughter houses and retail meat shops from Hyderabad Karnataka Region, India. APCBEE Procedia 8:364-369.

14) Kumar N, Rao TKS, Varghese A, Rathor VS.2013. Internal parasite management in grazing livestock. Journal of Parasitic Diseases. 37(2): 151-157. DOI: 10.1007/s12639-012-0215-Z

15) Levine AD, Asano T, 2004. Peer Reviewed: Recovering Sustainable Water from Wastewater. Environmental Science and Technology 38(11):201A-208A. DOI: 10.1021/es040504n

16) Maranan RFR, Paraso MGV, Alcantara AJ, Espaldon MVO, Alaira SA, Sevilla CC, Valdez CA, 2008. Operations and waste management of slaughterhouses in the Province of Laguna. Journal of Environmental Science and Management 11(2):32-41

17) McDaniel CJ, Cardwell DM, Moeller RB Jr \& Gray GC. 2014. Humans and cattle: a review of bovine zoonosis. Vector Borne and Zoonotic Diseases. 14(1):1-19. DOI: 10.1089/vbz.2012.1164

18) Mulu A, Ayenew T, Berhe S, 2013. Impact of slaughterhouses effluent on water quality of Modjo and Akaki river in Central Ethiopia. International Journal of Science 4(3):899-907.

19) Mummed YY, Webb EC. 2015. Operation, facilities, and management in public and private slaughterhouses in Ethiopia. African Journal of Agricultural Research 10(7): 623-630. DOI: 10.5897/AJAR2014. 9322

20) Murrel KD.2013. Zoonotic foodborne parasites and their surveillance. Revue scientifique et technique (International Office of Epizootics) 32(2):559-569.

21) National Meat Inspection Service (NMIS), 2014. NMIS 2014 Annual Report of Accomplishment, NMIS Publication.

22) Ninios T, Lunden J, Korkeala H, Fredriksson- Ahomaa M, 2014. Meat inspection and control in the slaughterhouse. John Wiley \& Sons, Ltd., West Sussex, UK.

33) Palmer SR, Torgerson P, Brown DWG (eds). 2011. Oxford Textbook of Zoonoses. 2nd edn. Oxford University Press, UK.

34) Rosengren LB, Gow SP, Weese JS, 2010. Antimicrobial Use and Resistance in Pigs and Chickens. A review of the science, policy, and control practices from farm to slaughter. Canadian Journal of Infectious Diseases and Medical Microbiology 21(3):123-124.

35) Sarairah A, Jamrah A, 2008. Characterization and assessment of treatability of wastewater generated in Amman slaughterhouse. Dirasat. Natural and Engineering Sciences 35(2):71- 83.

36) Sarwar M. 2015. Insect vectors involving in mechanical transmission of human pathogens for serious diseases. International Journal of Bioinformatics and Biomedical Engineering 1(3):300-306. 